\title{
O controle do corpo feminino no programa Encontro com Fátima Bernardes: subjetividade, texto e contexto
}

\author{
The control of female body in the program Encontro com Fátima Bernardes: \\ subjectivity, text and context
}

\author{
Jussara Peixoto Maia \\ Doutora em Comunicação e Cultura Contemporâneas pela Universidade Federal da Bahia, professora do curso de Comunicação \\ Social da Universidade Federal do Recôncavo da Bahia e do Programa de Pós-Graduação em Mídia e Formatos Narrativos da UFRB \\ e pesquisadora da Universidade Federal da Bahia. \\ <jussaramaia@uol.com.br>
}

\section{Igor Sacramento}

Doutor em Comunicação pela Universidade Federal do Rio de Janeiro (UFRJ), pesquisador do Instituto de Comunicação e Informação Científica e Tecnológica em Saúde da Fundação Oswaldo Cruz (Laces/lcitct/Fiocruz) e professor do programa de PósGraduação da UFRJ.

<igorsacramento@gmail.com>

\section{Valéria Vilas Bôas}

Doutoranda em Comunicação e Cultura Contemporâneas pela Universidade Federal da Bahia (UFBA). <lelavbs@gmail.com>

\section{RESUMO}

Neste artigo, analisamos como o programa Encontro com Fátima Bernardes, da TV Globo, constrói posições de sujeito para o feminino articuladas a um perfil dominante de feminilidade, estabelecendo ressonâncias e tensões com valores que são disputados e atualizados na sociedade contemporânea. Observamos as estratégias da produção utilizadas para enfatizar características de um modelo dominante de subjetividade feminina no processo de definição do formato. A análise se dá em três períodos de mudança de cenário e mostra suas implicações nas relações entre o formato e a forma de construção do feminino. Também consideramos as articulações entre as estratégias de produção e os modos de reconhecimento e consumo televisivos por meio de comentários pela página oficial do Encontro com Fátima Bernardes no Twitter. Assim, demonstramos como a forma de conceber o feminino no programa reverbera uma disposição cultural dominante em relação ao lugar da mulher configurada por meio do discurso patriarcal.

\section{ABSTRACT}

We analyze in this article how the program Encontro com Fátima Bernardes, produced and broadcasted on TV Globo, constructs subject position to females articulated to a dominant profile of femininity, establishing resonances and tensions with values that are disputed and updated in contemporary society. We observe the production strategies used to emphasize model features of female subjectivity in the process of format definition. The analysis refers to three periods of change of scenery and shows its implications in the relations between the format and the form of construction of the feminine. We also consider the links between production strategies and modes of television recognition and consumption through comments on the official page of the Encontro com Fátima Bernardes on Twitter. Thus, we show how the way of conceiving the female at the program reverberates a dominant cultural disposition in relation to the place configured to the woman through the patriarchal discourse.

Keywords: Television. Female. Subjectivity. 


\section{Introdução}

Em 2012, Fátima Bernardes, a apresentadora do telejornal de maior audiência do país que dividia a bancada de notícias com o então marido, William Bonner, começa a operar uma transformação na sua carreira com a estreia de um programa matinal. Anunciada desde a sua saída do Jornal Nacional, em dezembro de 2011, a nova atração foi apresentada como ideia e projeto da jornalista que falava do novo programa como a realização de um sonho: Não é fácil você imaginar que vai deixar o produto jornalístico de maior audiência do Brasil para buscar um sonho. De início era uma ideia que virou uma vontade enorme, até o dia que ele combinou para eu apresentar o primeiro projeto (Pinheiro, 2011).

Lançado em 25 de junho de 2012, o programa Encontro com Fátima Bernardes se filia a uma linhagem de programas de variedades destinados ao público feminino, presentes na televisão brasileira já na década de 50 , com a primeira produção, OMundo é das mulheres, na TV Paulista, em 1955, comandado por Hebe Camargo (IMPRENSA, 2010), a Revista Feminina, apresentado por Maria Tereza Gregori, na TV Tupi, em 1958 (Pinheiro; Reckziegel, 2006) e a Boa tarde, de Cássio Muniz (Esquenazi, 1993), lançado no ano seguinte, na mesma emissora. Estas foram produções pioneiras, que acolheram as questões domésticas, relativas aos cuidados com a casa, a família, os prazeres culturais e, também, aquelas relativas à capacitação da mulher para o mercado de trabalho. Comandado por uma jornalista que se destacou no telejornalismo brasileiro como apresentadora do Jornal Nacional, telejornal de maior audiência, mais antigo e de maior prestígio no país, o programa é examinado como parte de um processo de afirmação e questionamento do discurso patriarcal em relação à mulher no Brasil.

A investigação realizada no marco dos Estudos Culturais observa a produção cultural articulada à disputa por hegemonia através de valores e sentidos, o que exige perceber de modo integrado a historicidade do programa e da cultura. Este esforço investigativo parte do conceito de cultura formulado por Raymond Williams (2000), como modo integral de vida e considera a televisão como uma tecnologia e uma forma cultural (Williams, 1997). Para Williams (1997), qualquer desenvolvimento de uma forma cultural (como a de um talk show, por exemplo) expressa, ao mesmo tempo, configurações relacionadas a práticas sociais. Assim, as formas culturais devem ser analisadas em si mesmas em articulação com os processos sociais, considerando a existência de relações complexas entre cultura e sociedade, dentro da perspectiva que desenvolveu como materialismo cultural. Isso não quer dizer que, para Williams, as mudanças na forma cultural sejam necessariamente uma consequência de transformações 
sociais mais amplas. Williams é muito cuidadoso para evitar articulações que sugerem que a mudança de forma cultural segue necessariamente as formulações sociais, técnicas ou econômicas que poderiam provocar acusações de materialismo mecânico ou ortodoxo. Em Marxismo e literatura, por exemplo, Williams (1979) explicitamente reteoriza a famosa e altamente contestada metáfora de base-superestrutura de uma maneira que desafia acusações de um movimento causal mecânico e unidirecional da base para superestrutura. Em vez disso, Williams descreve um movimento de articulação entre a cultura e as condições objetivas do mundo social como é vivido com a proposição do que denominou de materialismo cultural. Por exemplo, a mudança na forma cultural é formulada como a mediação entre a estrutura e a agência, na inter-relação entre o agir com intenção no mundo social e o mundo social que informa as intenções e as práticas.

A análise da relação entre texto e contexto, ou, nos termos de Williams (2000), entre produto cultural e condições sociais concretas, é parte da elaboração de uma perspectiva teórico-metodológica. Neste artigo, como já anunciamos, analisamos essa relação a partir dos Estudos Culturais, buscando particularmente observar um produto televisivo, ao mesmo tempo, como tecnologia (como um meio técnico moldado como parte da construção de sentidos no interior de pressões e limites determinantes de uma cultura da sociedade capitalista) e como forma cultural (como um conjunto de produtos culturais - programas, no caso - se constituem no conjunto de determinadas relações de produção, modos de narração e tipos de interação entre o produtor, o artista/jornalista e o público). Essa abordagem permite, por exemplo, pensar como determinada forma cultural televisiva se articula com determinado sistema de relações sociais.

Para este artigo, a relação entre o textual e o contextual, entre o cultural e o social, estará presente especificamente na presença do discurso patriarcal como eixo organizador de enunciados sobre o feminino no programa Encontro com Fátima Bernardes. O vínculo do programa com o público feminino orientou o diálogo com os debates relativos às questões de gênero, a partir da relação que o programa propõe à audiência ao elaborar uma definição de mulher, como categoria que opera a partir da noção binária masculino/feminino, excluindo outras possibilidades de existência fora dessa concepção (Butler, 2016).

Nossa análise procura identificar no programa estratégias que convocam os indivíduos a assumir determinada posição de sujeito em práticas discursivas, historicamente específicas, destinadas à regulação, à disciplina e ao controle (Foucault, 2013). Encontro com Fátima Bernardes é compreendido como dispositivo (Foucault, 2011) ao integrar uma formação composta por relações 
de força que sustentam e são sustentadas por saberes acerca de uma definição específica, neste caso, do que é ser mulher, dentro da concepção binária, "[...] totalmente descontextualizada, analítica e politicamente separada da constituição de classe, raça, etnia e outros eixos de relação de poder, os quais tanto constituem a 'identidade' como tornam equívoca a noção singular de identidade" (Butler, 2016, p. 22).

O conceito foucaultiano de dispositivo auxilia na compreensão das posições de sujeito inscritas no programa que se anuncia para um público-alvo e reivindica o domínio de saberes relativos ao gênero. A produção oferece à recepção lugares regulados e controlados, pois são destinados à constituição de identificações específicas e excludentes, em negociações nos múltiplos processos subjetivação, que estão fora do alcance deste texto. "O dispositivo, portanto, está sempre inscrito em um jogo de poder, estando sempre, no entanto, ligado a uma ou a configurações de saber que dele nascem, mas que igualmente o condicionam" (Foucault, 2011, p. 246).

Na leitura feita por Agamben (2009), o conceito de dispositivo tem importância decisiva no trabalho de Foucault ao permitir a análise da relação entre os seres viventes e a história, tornando possível a investigação das estratégias de poder que operam para modelar, controlar, regular os indivíduos. Constituído e construtor dos sentidos históricos reivindicados pelo entretenimento, como prática social e como indústria mundial, o Encontro enfatiza o apelo à diversão, ao lazer, à brincadeira e à dança, vinculado a relatos sobre o cotidiano, como produção cultural e, também, como dispositivo. Afinal, na "[...] raiz de todo dispositivo está, deste modo, um desejo demasiadamente humano de felicidade, e a captura e a subjetivação deste desejo, numa esfera separada, constituema potência específica do dispositivo"(Agamben,2009, p.49).

O conceito de posição de sujeito auxilia na compreensão das posições oferecidas à recepção para a constituição de identificações, em negociações presentes em múltiplos processos subjetivação que estão fora do alcance deste texto. As posições de sujeito participam de um processoespecífico de convocação dos indivíduos a serem sujeitos de determinados discursos. Geralmente, elas são assumidas a partir da subordinação de indivíduos às expectativas dos discursos sobre o que é normal, permitido e necessário. A partir de saberes, formados através de discursos, sobre o mundo e sobre si mesmos os indivíduos são subjugados para se tornarem sujeitos da enunciação. Nesse sentido, o que está em questão não é a linguagem (falada, contudo, apenas pelos homens e mulheres), mas, sim, esse ser que, do interior da linguagem pela qual está cercado, se representa, ao falar, o sentido das palavras ou das proposições que enuncia e se dá, finalmente, à representação da própria linguagem (Foucault, 
1995). Ou seja, a questão a ser considerada é o ser humano em sua própria positividade (ser que vive, trabalha, fala), em tudo aquilo que permite a esse ser saber ou procurar saber o que é a vida, em que consiste o trabalho e suas leis e de que modo ele pode falar em determinadas situações.

Em outras palavras, as posições de sujeito são como diretrizes - conduções de condutas - que, em cada situação específica, agem no posicionamento enunciativo (interpelação, chamamento ou convocação) de indivíduos como sujeitos da normalidade, do desejável, do saudável ou da beleza, mas também da anormalidade, do indesejável, da doença ou da feiura, por exemplo. No entanto, como acrescenta Stuart Hall (2000), é preciso ter claro que, em vez de produzir uma identificação automática, unívoca e estável, as posições de sujeito, no interior da vida social, processam um conjunto de intensidades e mecanismos que produzem um lugar para o sujeito a partir do qual determinados saberes, valores e sentidos são associados a indivíduos como sujeitos em situações específicas. No entanto, é preciso ter em conta o seguinte:

Se uma suturação eficaz do sujeito a uma posição de sujeito exige não apenas que o sujeito seja convocado, mas que o sujeito invista naquela posição, então a suturação tem que ser pensada como uma articulação e não como um processo unilateral (Hall, 2000, p. 112, grifos do autor).

A perspectiva empregada nesta análise põe em diálogo a dimensão dos dispositivos como discursos que se organizam e operam para produzir ênfase em determinados sentidos e silenciar outros significados, com a dinâmica textual das posições de sujeitos inscritas nos textos como uma convocação que interpela a audiência a se identificar com opiniões e olhares específicos. Bastante debatido e problematizado, o conceito de identidade foi redefinido, sem perder sua importância central para a questão da agência e da política, afastando-se de uma abordagem essencialista e unívoca e assumindo uma nova e descentrada posição dentro do paradigma. Para Hall (2000), tal deslocamento pretende rearticular a relação entre sujeitos e práticas discursivas, prefere enfatizar o processo de subjetivação para práticas discursivas, e as políticas de exclusão em que toda essa subjetivação parece implicar a questão da identificação.

Foram observadas estratégias do programa no posicionamento do sujeito mulher e as formas de investimento ou desinvestimento, quando de certa resistência, por parte das convidadas em seus relatos e também pelas fãs-seguidoras da página oficial do programa no Twitter (@EncontroFatima), por meio de comentários. Portanto, nosso exercício de contextualização neste artigo diz respeito a demonstrar como determinadas posições construídas para 
o sujeito mulher no programa envolvem valores, significados e práticas sociais hegemônicas na cultura patriarcal da sociedade brasileira.

A nossa amostra é constituída pelos programas de 28 e 29 de junho e 02 de julho de 2012, que são programas da semana de estreia (há apenas um vídeo da estreia, dia 28, disponível no site do Memória Globo); 27, 28 e 29 de maio de 2013, período em que há a primeira grande mudança de cenário e o programa sai de um contexto comunicativo que sugeria um debate para um palco mais controlado com lugar definido para a banda, por exemplo; 20, 21 e 22 de janeiro de 2014, quando o programa muda mais uma vez para um cenário que sugere uma relação mais familiar se assemelhando a uma sala de estar; e 20, 21 e 22 de julho de 2016 como amostra da formatação atual do programa. As datas após o dia 20 se repetiram porque as mudanças de cenário aconteceram sempre nesse período do mês e quase sempre nos meses do meio do ano. O mês de julho foi escolhido para evitar a proximidade com as olimpíadas e impedir que a amostra ficasse muito marcada pelo tema. Na nossa análise, privilegiamos três eixos de abordagem que são percebidos como complementares e interligados no processo de comunicação, considerando que há produção, circulação e apropriação de sentidos sociais relacionados a formações mais amplas e reconhecendo que o programa atua como dispositivo:

1) as formas materiais do programa de modo a identificar relações entre a constituição de discursos sobre o feminino, recursos audiovisuais e o contexto comunicativo através da exploração de cenários para apresentadora, convidados, plateia, banda e artistas, de modo a normatizar condutas da mulher;

2) as questões da construção do feminino, pensando, inclusive, como tal operação favorece também a definição ou a invisibilidade de outros gêneros;

3) a recepção e seus modos de se relacionar com essa subjetividade proposta por meio dos comentários feitos por telespectadoras na página oficial do programa no Twitter.

\section{Quando o bebê nasce e a casa fica pronta}

Em 25 de junho, dia em que o Encontro com Fátima Bernardes foi ao ar pela primeira vez, Fátima entra em um cenário que vai sendo iluminado a partir da sua chegada ao som de uma música animada e leve e anuncia:

Olá, bom dia pra você, eu estou muito emocionada porque está começando o nosso primeiro encontro. Desde a minha despedida do Jornal Nacional, quando eu disse até breve, se passaram seis meses, dezenove dias, treze horas e alguns minutos de muito trabalho e de muita ansiedade como a gente acabou de ver [em referência ao clipe 


\begin{abstract}
de abertura com imagens dos bastidores da criação do programa]. Parece muito tempo, né? Mas foi bem menos do que uma gravidez, menos tempo do que a gente leva na construção de uma casa. E é bom lembrar que depois que o bebê nasce e a casa fica pronta o trabalho não acabou, ele está só começando, exatamente como vai acontecer aqui nos nossos encontros (Bernardes, 2012).
\end{abstract}

O primeiro take do programa, descrito acima, já aponta para a escolha de um lugar específico para o feminino a ser constituído por sentidos como alegria, festividade e leveza, clima evocado na música de fundo e pela marcação para o humor, na relação com o cotidiano das notícias. $\mathrm{O}$ anúncio mostra também a relação mulher-mãe na analogia com a gestação. Com frequência, a metáfora da gestação é acionada para caracterizar a realização ou o resultado de determinado projeto. Para o programa, evoca outra dimensão, que vem sendo explorada ao longo de sua história, o lugar de mulher-mãe-esposaprofissional bem-sucedida de Fátima Bernardes. Embora mais recentemente ela tenha se separado de William Bonner, até então, o programa se baseará nessa diversidade de papéis assumidos por ela ao longo de sua vida como forma de aproximação com o público, mas também como forma de autoridade para abordar os assuntos tratados na produção.

Inserido na grade em um horário tradicionalmente definido como a faixa cujos públicos preferenciais são o feminino e o infantil, o Encontro vai ao ar a partir das $10 \mathrm{~h} 40$ e promete misturar jornalismo e entretenimento com a presença de convidados e plateia, e a mediação da jornalista. Em sua estreia, o palco se constrói em 360 graus, propondo uma integração com a plateia e dá indício da proposta do Encontro com Fátima Bernardes de ser mais aberto às histórias de gente comum. A estrutura circular permitia que a plateia se misturasse aos convidados e à própria equipe da produção; permitia também uma configuração com dois palcos centrais, um oposto ao outro - o primeiro palco conferia certo destaque aos ocupantes e o seu oposto exibia os envolvidos na conversa mediada pela apresentadora misturados à plateia.

Na semana de estreia, Encontro com Fátima Bernardes tratou de adoção discutindo e exibindo histórias de pessoas comuns e a plateia, composta por convidados pela produção, é convocada o tempo todo. No dia 29 de junho de 2012, enquanto discutem o tema - na sequência de um $\mathrm{VT}^{1}$ sobre um casal homoafetivo que adotou um menino e sobre como as duas mães lidam com as saias justas da adoção no dia-a-dia - na plateia, Claudia, mãe de Raiane e

1 Usaremos o termo VT (vídeo-tape) para evitar a problematização acerca de referências do jornalismo na denominação reportagem. 
Rebeca, fala sobre o fato de ter adotado uma recém-nascida enquanto estava grávida; após sua fala, Lúcio, que estava ali como personagem de outra discussão (ele deixou de entrar no bolão dos amigos no dia em que eles ganharam na loteria), é convocado a falar sobre a experiência de criar um sobrinho após o falecimento de seu irmão. De volta a Cláudia, Lilia Teles pergunta: "Cláudia, quais são os comentários mais inadequados que você já ouviu e que você acha que não deviam ser feitos nunca na adoção?". Em um momento mais à frente, quando Lúcio, conta sua história do bolão de loteria, Luciano Huck liga para convidá-lo a tentar um prêmio no Caldeirão e Renata Ceribeli faz uma entrada ao vivo para contar que isso também já tinha lhe acontecido. A pauta, contudo, é feita a partir do cidadão comum.

Nessa primeira fase, as pessoas comuns, como Cláudia e Lúcio, são o mote principal do programa e mesmo os famosos são enquadrados a partir de uma perspectiva que Ihes considera a partir de uma faceta não célebre. É importante observar que o palco em 360 graus integra plateia e convidados, gente famosa e comum e constrói um contexto comunicativo que coloca as histórias de gente comum no centro do palco. O próprio espelho 360 graus, apresentado como cabine e instalado na entrada do estúdio, convidava o público a falar de si mesmo a partir de perguntas como "qual o seu maior sonho?", "o que você mudaria em você?", "como você comemorou a conquista do penta?" ou "qual foi a última vez que você ajudou alguém?" e funciona como mais um indício dessa centralidade. As pautas propostas e discutidas são apresentadas em VTs exibidos no grande telão que cerca o estúdio, contando histórias também de desconhecidos. Assim, quando o programa apresenta pessoas que se sustentam com bicos, o VT apresenta um vendedor de canga e um vendedor de sopa que conseguiu abrir um restaurante, e no palco, Fátima e Aline (repórter responsável pela produção da pauta) conversam com um pipoqueiro e um vendedor de balas.

Com a entrada de Vanessa da Mata, é a sua faceta mãe, pouco conhecida do grande público, que vem à tona - convidada para também falar sobre adoção, e introduzida por Fátima:

Uma das nossas ideias pra esse programa é trazer sempre pessoas pra conversar sobre assuntos que a grande maioria não imagine que são de interesse dessas pessoas, então hoje a Vanessa não está aqui pra falar da carreira dela, dos shows que ela faz, das músicas, dos planos pro futuro profissional, a Vanessa veio porque a adoção é um assunto que fala diretamente a ela. [...] Eu sei que você não gosta muito de falar desse assunto e exatamente por isso a gente achou tão interessante que você viesse aqui falar com a gente (Bernardes, 2013). 
A fala de Vanessa, em resposta, assume um lugar de atribuição de autoridade, mas também de familiaridade com Fátima:

Com certeza. É um prazer tá [sic] aqui no seu programa [Vanessa se aproxima de Fátima e pega na sua mão], você é a pessoa certa pra falar disso porque tem um conceito de seriedade e de prestígio na sua personalidade, na sua maneira como você fala, na doçura com que você trata dos assuntos, eu acho que você é a pessoa certa pra falar disso e pra dar credibilidade pra isso (Da Mata, 2012).

A abordagem do tema adoção nas edições da primeira semana de estreia do programa foi um exemplo da força da sobreposição dos papéis mulher e mãe numa mesma categoria, estabelecendo uma espécie de marco na elaboração de um sentido de mulher que se expressa de modo vinculado à maternidade. Esta arquitetura trata a mulher como um significante dependente, a ser preenchido por sentidos culturais atribuídos à mãe, como bondade, renúncia pessoal e amor incondicional. Na amostra disponível, nos dias 28 e 29 de junho de 2012, são as mulheres que falam sobre o assunto, no estúdio ou em reportagens, inclusive no caso de uma relação homoafetiva que toma como exemplo um casal de lésbicas, no VT. Entre as entrevistadas, estão pessoas comuns e celebridades, como Vanessa da Mata que falou sobre a adoção de três irmãos.

Nesse diálogo, é interessante observar a valoração da doçura como uma característica importante do feminino. A configuração social de determinadas especificidades do sujeito-mulher, e particularmente o comportamento individual feminino, materializam as relações de poder que os produziram e as miríades de maneiras em que essa produção é realizada. Um olhar mais atento sobre o comportamento e os hábitos dos corpos tipicamente descritos e reconhecidos como feminino nessa conversa é, portanto, necessário: “[...] você é a pessoa certa pra falar disso porque tem um conceito de seriedade e de prestígio na sua personalidade, na sua maneira como você fala, na doçura com que você trata dos assuntos" (Da Mata, 2012).

O trabalho de duas teóricas feministas é inestimável aqui: Iris Marion Young (1990) e de Sandra Lee Bartky (1988). Estritamente falando, é importante para os propósitos do patriarcado que não haja nenhuma encarnação única que preencha perfeitamente o ideal estabelecido por ele. Além disso, parece duvidoso que mesmo dentro dos limites de uma cultura particular e de um período histórico específico, haja um ideal estático para a subjetividade feminina. As definições de comportamento, aparência e caráter femininos variam amplamente entre classes e etnias e o gênero é apenas um meio através do qual os corpos são construídos e categorizados. Diante desses múltiplos e variados fatores, as tentativas de discernir o que é feminino, como demonstram 
Young (1990) e Bartky (1988), podem correr o risco de ignorar outros fatores na construção da subjetividade e comportamento femininos, sustentando implicitamente um ideal de feminilidade como exclusão de mulheres de certas etnias ou classes em prol de um particularismo universal.

O programa Encontro com Fátima Bernardes faz essa exclusão ao elencar a maternidade, mas também a doçura, a fragilidade, a beleza, o compromisso com o trabalho, com os filhos e com a família. No contexto da cultura, as mulheres que são excluídas desse ideal normativo de feminilidade podem procurar se posicionar contra essa norma, que busca caracterizar as mulheres como tais, independentemente de raça, classe, orientação sexual e estilo de vida, em detrimento de concepção uma multifacetadada feminilidade.

O reforço desse papel essencialista para a mulher também permeou os comentários da página do Twitter à época. Muitas usuárias do Twitter se emocionaram com as histórias apresentadas:

Mirian Marada Silva @Miroks_201025 Jun 2012 Piedade, Brasil@ EncontroFatima Acho a adoção lindo, mas acho que o casal deve estar bem preparado! Pois a genética de cada indivíduo permanece. Sucesso! Bj

Sayonara @sazinhaalc 25 Jun 2012 @EncontroFatima Me emocionei muito com os depoimentos das crianças...

JULIANA DOLORES @julianadolores 25 Jun 2012 Viewtranslation @ EncontroFatima esta lindo e de se emocionar...

Luciana@LinoLuciana 25 Jun 2012 @EncontroFatima muito emocionada vendo o tema adoção, parabéns!!!!!!

Milla Freitas @MillaFreitas1625 Jun 2012 @EncontroFatima ESTOU ASSISTINDO, E JÁ CHORANDO DE TANTA EMOÇÃO COMO INICIO DO PROGRAMA.. PARABÉNS FATIMA..

Maria Aline Souza @maria_line 25 Jun 2012 EncontroFatima Estou ADORANDO o programa... e me emocionando muito com as estórias de adoção... PARABÉNS!

Tatiane Navarro @tatiane_navarro 25 Jun 2012 Viewtranslation @ EncontroFatima Emocionante o depoimento das crianças a espera de uma família. 
Nesses exemplos fica evidente o quanto a emoção era uma dimensão fundamental para o envolvimento com o programa. As telespectadoras, pelo Twitter, demonstram que esperam do programa a exibição de emoção por meio de experiências pessoais. $O$ tema da adoção abrange a família e sentimentos valorizados em nossa sociedade: amor, admiração, solidariedade e compaixão. Os assuntos abordados tradicionalmente em talk show giram em torno de questões psicológicas, como obsessões, vícios ou relacionamentos destrutivos e traições, mas também se concentram em questões sociais mais amplas, como desemprego, racismo, bullying, violência urbana e adoção, e ainda em temas anedóticos e leves, como superstição, moda e beleza. No entanto, cada tópico - do desemprego à experiência infortuna de uma celebridade - é enquadrado em termos psicológicos, geralmente destacando os sentimentos dos indivíduos (Shattuc, 1997). O caso de Encontro com Fátima Bernardes não é diferente, buscando contar com o relato de experiências pessoais emocionantes sobre os assuntos abordados dentro de uma linguagem terapêutica (Sacramento, 2016). Além disso, pela trajetória da apresentadora e pela identificação da emissora com a produção de telejornalismo como marca distintiva, no programa havia a inserção de noticiário nacional e internacional, além da produção de reportagens próprias sobre os temas abordados.

Outros tweets demonstram como algumas telespectadoras sentiramse à vontade para compartilhar experiências pessoais ou familiares coma adoção. A estrutura do programa calcada numa promessa de intimidade entre apresentadora, convidados, plateia e público, num clima de informalidade, associada à possibilidade de interação pelas redes sociais, permite maior sensação de proximidade com os temas abordados, modos de identificação e busca por comunicar experiências por meio das plataformas comunicacionais em rede do programa:

Marina @marininha_lindi 25 Jun 2012 @EncontroFatima Tenho uma prima e ela e adotada e amamos muito ela, ela é uma das alegria que temos em nossa familia.

Ana Maria de Faria @AnaMariadeFari2 25 Jun $2012 @$ EncontroFatima O programa está show!!!! Amei o destaque do tema adoção. Tenho um filho adotado, que chamo de filho do coração.

Tainá Ferreira @Tainaferreira1826 Jun 2012 @EncontroFatima tenho um irmão adotado e não dou a mínima para isso, porque de alguma forma ele é meu irmão de sangue e amo como os outros. 
Amanda Moreira @guinmoura 27 Jun 2012 @EncontroFatima minha irma tem uma filha adotiva, que hoje tem 15 anos, a adotou com 4, mas o irmão não teve a mesma sorte, está no abrigo inda.

naza @Silveriu 27 Jun 2012 @EncontroFatima minha irmã foi adotada com 9 meses. Hoje ela tem 25 anos. Deus fez ela nascer de outra mãe mas ela é igual a minha família.

Nesses relatos está presente uma circularidade entre o enfoque do programa com os relatos das telespectadoras, especialmente no que diz respeito à tradicional hierarquização entre "filho" e "filho do coração". Nesse sentido, a natureza biológica da família é implicitamente sobrevalorizada como o modo normal de ser pai e mãe. A adoção, de certa forma, é vista como um ato de solidariedade ou humanidade, mas não como efetivamente a constituição de uma família. Nos programas da semana, como abordamos, os relatos comoventes de mães e pais adotivos e de crianças adotadas apelam mais para a adoção como ato de bondade na resolução de desigualdades sociais e dramas pessoais (não poder ter filhos biológicos, por exemplo). No entanto, os programas durante a semana pouco exploram a construção social da família e mais valoram a origem biológica, reproduzindo a opinião corrente sobre a adoção. Quando não fazem diretamente isso, alguns remetem, por exemplo, ao fato de que "Deus fez ela nascer de outra mãe, mas ela é igual à minha família". Além de não expor o processo de construção social do sentimento de identidade familiar, trata a adoção num nível hierárquico de classificação de relação familiar mais baixo em relação à biológica, que mais se aproxima do modelo normatizado na medida em que o adotado se assemelha à família. Desse modo, as mães adotivas são posicionadas implicitamente pelo programa e por muitos comentários relacionados ao assunto nessa semana do programa como menos mães do que as biológicas. Além do aspecto envolvendo o parentesco, no tocante à definição da mãe, as práticas de adoção incidem nas representações de maternidade enraizadas na conexão entre mãe e natureza, traduzida na biologia e em interpretações psicológicas pela expressão "instinto materno" (Luna, 2005; Vieira, 2004). A associação da maternidade com o natural reforça a construção do ideal feminino de mulher-mãe, aquela mulher que não é mãe é vista geralmente como "falha", "incompleta" ou "menos mulher" (Badinter, 1985; Forna, 1999).

Já na última edição da semana, o programa afasta-se dessa concepção dominante ao mostrar a disputa de sentidos na construção cultural da maternidade quando destaca a coragem e responsabilidade da mãe que colocou o filho numa instituição para ser adotado. Fátima chama todos da plateia que 
adotaram ou foram adotados, destaca que a doação não é ilegal e lê a carta em que Paula Abreu, mãe adotiva que esteve no estúdio no dia do lançamento do programa, agradece a essas mães pelo gesto. Ainda que o programa não tenha abordado inúmeras variáveis de aspectos de classe e étnicos sobre o tema e, de certo modo, restitua à mãe uma generosidade constitutiva, a maternidade é posicionada também como uma escolha, mesmo na fase posterior ao nascimento, sem a desqualificação do ato de doar um filho.

Mantendo a perspectiva mais tradicional de vínculo com a casa, o programa reitera a relação entre mulher e tarefas domésticas, destacando a capacidade feminina para realizar procedimentos rotineiros. A destreza para dobrar uma camiseta em dois segundos é conferida à mulher através da competência de uma jovem paranaense, Ana Paula Detsch, que aparece no vídeo da internet como modelo para o desafio encenado numa brincadeira no centro do palco, em 28 de junho de 2012, pelo parceiro de Fátima Bernardes, Lair Rennó. Ao final, o jornalista participa e embola a camiseta sem dobrá-la, enquanto todos riem, usando o humor para mascarar e desativar as relações de poder na micropolítica que isenta o homem do aprendizado de uma das tarefas domésticas mais banais, conferindo implicitamente à mulher sua execução.

\section{Isso acontece de verdade}

Acreditando que os programas televisivos podem ser tomados como lugares de construção de subjetividade, é a noção de dispositivo, tal como descrita por Giorgio Agamben (2009), em articulação com Foucault (2011), que nos permite afirmar que, ao longo do tempo, o Encontro com Fátima Bernardes foi colocando o sujeito não célebre em diferentes posições a partir dos seus aspectos materiais. A mudança de cenários ao longo do tempo é, talvez, o principal indício de como os aspectos materiais do programa foram usados para inscrever um lugar específico para a pessoa comum. Paulatinamente, a própria apresentadora deixa um pouco de lado o lugar de jornalista com credibilidade e dignidade e convoca o papel de mãe e mulher, possível a qualquer telespectadora, e configura de modo explícito uma série de disputas e tensões a respeito do lugar do feminino, tomado sempre a partir do seu corpo e da sua experiência.

Assim, se a casa, os filhos e o zelo doméstico marcaram sua fala na estreia do programa, na primeira mudança significativa pela qual o cenário passa, em 2013, é o próprio cenário que simula o aconchego do lar e a noção de familiaridade aparece mais forte na fala de Fátima: "Olá, hoje é segunda-feira, 27 de maio e esta é a nossa casa nova. A partir de hoje, serão aqui os nossos encontros diários" (Bernardes, 2013). Ao convocar seus parceiros, Marcos Vera e 
Lair Rennó, Fátima pergunta: Gostaram da casa nova?; Veras responde: "Gostei, quero saber onde é o meu quarto" (Veras, 2013); Lair: "É esse aqui mesmo" (Rennó, 2013); Fátima: “Esta é a nossa área de bate-papo mesmo" (Bernardes, 2013).

O novo cenário tem um sofá, uma cadeira forrada com bonequinhas para a apresentadora, cadeiras de apoio para os outros integrantes de sua equipe. Em um palco lateral, há um espaço para a presença de uma banda. A organização do espaço mais central às trocas comunicativas no programa tem uma forte marcação da referência ao feminino como resultado da fusão dos lugares sociais da mulher e da mãe. Este sentido está presente na utilização de uma cadeira com 225 bonecas de pano, reconhecida com destaque como o lugar de Fátima, numa marcação inexistente na organização do cenário anterior. O móvel é uma obra exclusiva, presenteada pelos irmãos Campana, e expressa valores da cultura patriarcal no Brasil ao fundir a maternidade com a condição de ter o corpo e com a biologia de mulher. Nessa nova configuração, os convidados se sentam no sofá que fica ao lado da nova cadeira de bonequinhas de Fátima.

As telespectadoras comentaram as mudanças de cenário no Twitter:

Sandra @carrijosandra 27 May 2013 @EncontroFatima Adorei a decoração nova.

Eveline Silva @eveline22silva 27 May 2013 @EncontroFatima tá lindo, mas perdeu o aconchego q a gente sentia da plateia ao seu redor. E o telão era lindo :/, mas é sempre bom mudar.

Sabrina Delduque @sabrinabati 27 May 2013 @EncontroFatima não gostei não. Perdeu a marca do programa que era deixar o público perto. Assim, ficou igual aos outros!!

Bianca Pereira @biancapereira5627 May 2013 @EncontroFatima linda a casa nova amei a cadeira da Fátima

Já nesse programa, com a mudança de cenário, é bastante significativa a diferença na relação com os convidados, pois agora os famosos assumem de maneira central o lugar de fonte. Para abordar o tema envelhecimento com a nova geração dos sessentões, estão presentes os atores Kadu Moliterno, Evandro Mesquita e Otávio Augusto e o ex-jogador Júnior que já estava ali para falar de futebol. Esta escolha expressa uma diferença bastante significativa em comparação com a edição em que adoção foi o tema debatido, com pessoas comuns,aoladodacantoraVanessadaMata,únicafamosa.Olugardosespecialistas 
não célebres e dos espectadores presentes passa a ser a plateia, espaço que se define por exclusão, um não-palco que lhe é oposto espacialmente e, inclusive, externo ao enquadramento da câmera durante a maior parte do tempo.

Nessa configuração, o destaque é para os artistas, enquanto Fátima e a equipe se deslocam muito pouco e a interação com a plateia quase inexiste. Os famosos falam do tema do dia a partir de suas experiências e também de questões pessoais, como Evandro Mesquita que conta o início de sua carreira e tem sua história reconstituída através de um VT e de depoimentos de outros artistas. O cantor mesmo chama o espectador para acompanhá-lo em um tour no Leblon, no trajeto que ele fazia entre sua casa e seu primeiro trabalho, no Teatro Ipanema: "Convido vocês pra fazer esse trajeto comigo e a gente vai tentando lembrar desses bons tempos aí do começo, ok? Chega junto, vamos lá" (Mesquita, 2013). Os outros convidados que estão no sofá participam da conversa sobre Evandro, que recebe um tratamento diferenciado.

Como parte da ênfase na presença de artistas e no embaralhamento entre o cotidiano vivido e o drama encenado, o programa destaca a programação da TV Globo, que é tomada também como pauta para definição de temas. Ao discutir sobre assédio moral, no dia 28 de maio de 2013, o VT introduz o tema através de situações de novelas da emissora e do relato de populares. De modo didático, uma procuradora do Ministério Público do Trabalho identifica abusos cometidos por personagens no VT exibido, e no estúdio, participa do programa na plateia, o não-palco. O tema é encenado no palco, a partir de uma situação de novela com a presença de um ator: "A gente tá com o José Loreto aqui, ele vivia o Darkson de Avenida Brasil e em uma das cenas do Darkson havia uma situação em que a, naquele momento chefe dele, a Suelen, exigia que ele se vestisse de mulher" (Procuradora..., 2013). Fátima anuncia também a presença de Thiago Ferreira, um vendedor que passou por assédio moral. Da plateia, Thiago dá o seu depoimento e diz que procurou a justiça porque na empresa em que trabalhava era obrigado a ler um termo de incompetência e a usar uma lanterna no bolso se tivesse sido o último nas vendas. Ele diz: "Na novela, claro é brincadeira, mas isso acontece de verdade" (Ferreira, 2013).

As diferentes opiniões sobre as mudanças são menores do que os relatos sobre o tema abordado no período: o assédio moral. Muitas telespectadoras relataram como sofreram ou ainda sofriam com relações problemáticas no trabalho:

Paula Inacio @PaulalnacioO 28 May 2013 @EncontroFatima Já fui vítima de assédio moral no meu trabalho, isso foi muito triste porque eu era muito jovem, era meu primeiro emprego! 
Ingrid Silveira @Ingrid_Silveira 28 May 2013 @EncontroFatima Por causa de assédio moral de uma ex-chefe, desenvolvi stress agudo e síndrome do pânico.

Caroline Braz @carolinebraz2 28 May 2013 View translation @ EncontroFatima Não sei se é considerado o assédio, mas minha chefe colocou a culpa do erro uma colega em mim, e ainda disse bem alto para..

Avani vitor @avanivitor 28 May 2013 @EncontroFatima tive uma patroa q gostava muito de umilhar as pessoas, q eu tinha ate medo dela quando chegava

Por meio desses breves relatos, podemos observar o quanto o assédio moral produz subjetividades vulneráveis ou risco diante de problemas cotidianos do trabalho. Na sociedade contemporânea, muitos dos conceitos da psicologia foram submetidos a mudanças semânticas. Essas mudanças conceituais seguem uma tendência consistente. Conceitos que se referem aos aspectos negativos da experiência humana e comportamento têm expandido seus significados para que eles agora abrangem uma gama muito mais ampla de fenômenos que antes. Há uma expansão contínua da gama de experiências humanas que podem ser rotuladas como abusivas, de tal forma que a negligência e o insulto não intencional se confundem com a violência física ou o assédio moral, incorporados em uma categoria para todos os fins genéricos.

Frank Furedi (2004) argumenta que essas mudanças são representativas de uma ampla transformação mais recente nas sociedades ocidentais contemporâneas, no sentido do que ele descreve como um imperativo terapêutico. Por isso ele quer dizer que praticamente todas as esferas da vida se tornaram sujeitas a uma nova cultura emocional. Seu ponto aqui é que as experiências que, uma vez foram consideradas como elementos ordinários da vida (decepção, isolamento, cansaço, separação, frustração), estão agora sendo redefinidos como síndromes e necessitando de intervenção médica. As pessoas já não são considerados capazes de lidar com as emoções que essas experiências produzem sem a intervenção de conselheiros, terapeutas ou médicos. Furedi (2004) sustenta que a crescente dominação da cultura terapêutica é problemática porque promove uma concepção do sujeito humano como indivíduos fracos, frágeis e impotentes, e reformulado como vítimas. No entanto, ao mesmo tempo, é valorizada a capacidade de mudança, de superação, a partir de um gerenciamento eficaz das próprias emoções (Illouz, 2003). É muito marcante em na cultura contemporânea a importância dada ao testemunho público da vítima, 
identificada e celebrada como "sobrevivente" aos sofrimentos e tormentas por que passou. O testemunho da vítima conta, então, com uma forte tonalidade exemplar, fazendo com que a experiência traumática se transmute sob o ethos motivacional e capitalize sobre a tendência atual de autoajuda que usa o sofrimento como meio de desenvolvimento pessoal e de acesso à "verdade interior" dos sujeitos que apenas pôde ser alçada pela vivência de momentos marcados por abusos, violências, desgraças e angústias excessivas (Sacramento, 2016). Alguns relatos, por sua vez, buscam afirmações em posições de sujeitos baseadas na superação:

Carmen @CarmenBoni 28 May 2013 @EncontroFatima sim estou sofrendo mas resolvi estudar o comportamento humano já que vou me aposentar em 4 meses para superar e entender.

Nara Rodrigues @nararod9452874928 May 2013 @EncontroFatima Já passei por vários, mas eu me sentia tao acoada, que nao tinha estimulo nem pra recorrer!

Andreza @Andreza3728 May 2013 @EncontroFatima Sofri assédio moral e denunciei. que bom que a justiça foi feita!

Luana Polónia @lupolonia 28 May 2013 @EncontroFatima já sofri assédio moral por minha encarregada ter medo de ser substituída! Tive que ser mudada de sede e me dei muito bem!

Por outro lado, há na cultura terapêutica contemporânea uma dependência autoritária de profissionais especializados para garantir a saúde mental e o bem-estar de cada um. Furedi (2004) alega que suas críticas não são dirigidas especificamente aos psiquiatras e conselheiros, mas sim com o que ele vê como uma tendência mais geral para normas culturais terapêuticas e emocionais, em que se presume que as pessoas são incapazes de lidar com as dificuldades da vida. A ênfase implacável dirigida para a necessidade de aumentar a autoestima, e da expansão contínua das categorias de trauma para abranger cada vez mais as experiências da vida, incorporando uma visão diminuída e fatalista da agência humana. Sob a rubrica de terapia, os indivíduos são retratados como sofrendo de algum tipo de déficit de controle emocional, o que garante um estado permanente de vulnerabilidade ou risco. Entre os relatos que demonstram essa vulnerabilidade, destacamos os da telespectadora Regina Diniz Outeiro: 
REGINA DINIZ OUTEIRO @REGINAOUTEIRO 28 May 2013 @ EncontroFatima síndrome de pânico. Eu e mais 2 colegas passamos a tomar antidepressivos. Pena que naquela época não se falava em assédio...

REGINA DINIZ OUTEIRO @REGINAOUTEIRO 28 May 2013 @ EncontroFatima Vai perder a função. Não perca tanto tempo no atendimento ao cliente. Resultado: cai numa depressão profunda.

REGINA DINIZ OUTEIRO @REGINAOUTEIRO 28 May 2013 @ EncontroFatima Sofri assédio moral de uma gerente em um banco estatal. Todos os dias era o mesmo assunto: você vai ser transferida.

Como uma expansão do círculo moral em novas e mais leves formas de danos, o comportamento abusivo, dominador e discriminatório anteriormente tolerado passa a ser extremamente problemático, e estende-se o cuidado profissional a pessoas que experimentam a adversidade e o sofrimento que uma vez teria sido ignorado. Há uma crescente tipificação moral que diferencia vítimas, agressores e testemunhas. As vítimas são as moralmente mais valorizadas pela situação de fragilidade em que se encontram, uma vem que são entendidas como não tendo qualquer responsabilidade sobre os danos que sofrem. Os agressores, pelo contrário, são totalmente responsáveis pelos danos que consciente e perversamente provocam em seus subordinados. Já as testemunhas são como que cúmplices do assédio moral, quando não apoiam as vítimas em se livrarem da situação de intimidação. Há uma configuração moral das vítimas de assédio, como abordado no programa e nos comentários no Twitter, definidas por seu sofrimento, vulnerabilidade e inocência. Com isso, há diminuição da agência para superar a própria situação. No talk show, como mostramos, essa linguagem terapêutica está bastante presente nas formas de aconselhamento (jurídicas, psicológicas, baseadas em experiências pessoais) que foram exibidas ao longo da semana, valorizando as vítimas. São elas - e apenas elas - que relatam suas próprias experiências de abuso e sofrimento.

A narrativa terapêutica nos talk shows busca se combinar com uma experiência televisiva potencialmente feminina, na medida em que há uma preponderância de mulheres anfitriãs, convidadas e especialistas, um foco em temas de especial interesse para as mulheres, um espaço para as mulheres falarem sobre suas próprias experiências, uma atmosfera de afirmação e escuta íntima (Gill, 2007, p. 159-170). Por isso, acreditamos que essa esfera de intimidade e informalidade produz práticas de compartilhamento de experiências pelas telespectadoras pelo Twitter. 


\title{
Mi casa, sua casa
}

Ao referir-se ao cenário do programa sempre como se fosse a sua casa, Fátima inscreve a produção no âmbito familiar também dos espectadores minha casa, sua casa. A metáfora volta a funcionar em mais uma mudança de cenário, em 2014, quando a apresentadora convoca um sentido de familiaridade que prolonga o ambiente doméstico de Fátima para o palco:

\begin{abstract}
Olha só que delícia, você sai de férias, volta e a casa tá completamente nova e o melhor de tudo, você não ouviu uma batida de martelo, não sentiu um cheirinho de poeira, não sentiu cheiro de tinta... Eu não sei se é porque eu tô passando por esse momento na minha casa que está completamente em obra e chego aqui, olha só, tá tudo, olha só, gente, tudo novinho e sem nenhum barulho [...] (Bernardes, 2014).
\end{abstract}

O lugar dos populares se torna cada vez mais externo ao palco e já não é necessariamente a partir deles que se pautam os assuntos discutidos. Em 21 de janeiro de 2014, o debate sobre o tema mulheres separadas começa com a cantora Luiza Possi, ao lado de convidados presentes no palco, e só no final há alguma participação da plateia.

A condição de estar solteira é abordada com a construção do feminino como uma dimensão relativa ao corpo sexuado da condição biológica da mulher e a ela são atribuídas características que denotam elevado grau de vulnerabilidade a algumas condições, como a de um ser que perde sua inteireza ao se separar, sempre, do homem. Fátima convoca Luiza Possi para uma dinâmica sobre como a mulher separada é vista: "Essa mulher, às vezes, é olhada com uma certa desconfiança, tá esperando alguém, não, não vai chegar ninguém, eu tô sozinha [...]". Na brincadeira, a cantora fixou adjetivos como"sem noção", "carente" ("[...] vou colocar aqui no estômago porque você fica carente e come e depois ficar gorda e horrível"), "corajosa", "ansiosa", "carinhosa", em um manequim com vestido preto curto que a representou após o término de um namoro (Possi, 2014). Fátima a interpela: "Mas a mulher que vai pra pista, você acha que ela está com essas características?" (Bernardes, 2014). Luiza critica os adjetivos disponíveis para essa caracterização (desajeitada, desesperada, grudenta, descolada, carinhosa): "Que horror, tinha que ter um 'de boa"' (Possi, 2014). O ator Júlio Rocha, outro convidado, também fala sobre já ter sofrido após o término de um namoro, e duas pessoas da plateia, um homem e uma mulher, também contam suas histórias. Enquanto mulheres da plateia declaravam sentir preconceito por ficarem com os filhos, após a separação, 
quando buscavam novas relações, o ator Júlio Rocha (2014) foi aplaudido ao expressar o sentido hegemônico do patriarcado brasileiro que posiciona o homem como indivíduos apaixonados por mulheres: "os homens amam as mulheres, independente se elas são solteiras, viúvas, separadas. A mulher é o ser mais precioso do mundo". Esta declaração contraria os dados do Ministério da Saúde, no Mapa da Violência 2015: homicídio de mulheres no Brasil, que mostram que dos 4.762 feminicídios, 33,2\% foram cometidos por parceiros e ex-parceiros. Para resolver o que é construído como problema no programa e a mulher conseguir"voltar para a pista"após uma separação, o jornalista Lair Rennó dá dicas coletadas em livros e na internet e Fátima ouve a opinião da plateia.

É importante destacar que o momento que permite que a plateia se manifeste é justamente o momento em que o programa aconselha, dá dicas, moraliza, controla sob a forma de diálogo. Ao apresentar a última dica, Lair diz que ficou com dúvida: "Não saia com um grupo imenso de mulheres. Por que isso atrapalharia?" (Rennó, 2014). Na plateia, Fátima pergunta: "Você acha que sair com um grupo muito grande de meninas atrapalha na hora da paquera?" (Bernardes, 2014). Uma moça (2014) responde: "Acho que sim, acho até que por uma questão de preservação da sua imagem porque muita mulher reunida num lugar só acaba criando muito tumulto". Fátima não invalida as opiniões, não faz muitos comentários na sequência, se coloca numa posição de ouvinte. Em seguida, pergunta a um homem: "Você acha que se você olhar pra um grupo de muitas mulheres juntas você acha complicado, mais fácil chegar se ela estiver sozinha?" (Bernardes, 2014). A pergunta sugere que Fátima busca nuances de opinião e é ela quem controla o dito - o microfone nunca é passado à plateia, é sempre controlado pela apresentadora e as pessoas raramente são identificadas formalmente, especialmente se não são personagens convidados.

A edição de 20 de janeiro de 2014 é emblemática por expressar valores do patriarcado brasileiro de atribuir ao corpo sexuado da mulher heteronormativa a condição de objeto de sedução masculina que pretendia problematizar. Ao debater a situação da mulher que sai sozinha à noite, a partir do VT sobre o hábito da advogada Natascha Cima de ir a bares noturnos, com entrevista no local e com os convidados e a plateia, o programa não assume uma posição assertiva em defesa da liberdade da mulher, bandeira antiga da luta emancipatória. No VT, a personagem diz que os próprios garçons, às vezes, atendem mal e os mesmos declaram fazê-lo porque ao estar sozinha ela é considerada uma garota de programa. O analista de sistema Thiago Henrique da Costa fala que "não é possível" ela estar sozinha e o casal de engenheiros Jefferson de Lucena e Natália Ramos ratificaram o estranhamento. A engenheira chega a dizer: "Ela veio muito arrumada, aí já fica assim, né? O que é que ela tá fazendo por aqui? 
Ou ela tá esperando alguém ou com certeza está paquerando, vamos dizer assim. Foi isso que deixou um pouquinho tenso [sic]" (Ramos, 2014).

O estranhamento inicial com o preconceito sofrido pela personagem dá lugar à reiteração dos mesmos valores culturais patriarcais, uma vez que foi motivo de risos para todos no estúdio a iniciativa do parceiro de Fátima, Lair Rennó, de perguntar a atriz Sophie Charlotte qual o cinema que ela vai, depois de ouvi-la declarar que adora ir sozinha ao cinema e ao teatro. A condição da mulher como um significante fraco ou dependente é reiterada, em seguida, pela própria atriz ao confessar que não gosta de almoçar sozinha já que "tem sempre aquele olhar de'tadinha' porque não está esperando ninguém" (Charlotte, 2014). Esta concepção é reforçada pela opinião do psicanalista Francisco Daudt (2014), no papel do especialista que organiza e interpreta os sentidos em disputa nas falas sobre o tema, ao dizer que está correta a leitura do código social feita pela maioria das pessoas "se você se veste para matar e vai para um bar e senta e toma chopinho e passa o radar em torno". Mesmo após o questionamento feito por Fátima Bernardes (2014) de "qual é o mal de você estar sozinha e querer ir para um lugar e tentar achar uma companhia?", o especialista considera que "a mulher está à caça. É afirmação estatística que diz respeito à maioria. Código social!". A opinião do especialista foi rebatida apenas por Sophie: "Eu discordo. Eu acho que a gente tem que quebrar esse tipo de pensamento até em cima da beleza feminina... Se você quer sair sozinha, saia sozinha, fatal ou não" (Charlotte, 2014). A atriz foi aplaudida pela plateia, mas não houve qualquer manifestação de apoio da apresentadora do programa.

Se, como afirma Foucault (1977), os corpos individuais são produzidos com certas características identificáveis que se relacionam diretamente com a dinâmica de poder, então os corpos são textos que podem ser lidos para discernir as reivindicações (às vezes implícitas) do discurso dominante. Uma de suas afirmações centrais é que o corpo feminino é tratado pela sociedade como um objeto, uma coisa que existe separada dos objetivos da mulher como sujeito (e, muitas vezes, o contrário). As modalidades da existência corporal feminina têm sua raiz no fato de que a existência feminina experimenta o corpo como uma mera coisa - uma coisa frágil. A mulher, então, experimenta seu corpo como um objeto estranho, pesado e fraco que, dependendo do objetivo específico, precisa de uma transformação maciça ou de um tratamento com luvas. Diante da fragilidade de sua carne e dos perigos que ela enfrenta, a mulher tenta proteger seu corpo-vulnerável, restringindo seu alcance espacial e limitando seus esforços físicos.

Além disso, fica clara a permanência do controle do corpo feminino do século XIX, que acentua a divisão sexual das funções, dos papéis, das tarefas 
e dos espaços, associando lugares e posturas pré-determinadas ao masculino e ao feminino (Perrot, 2007). Assim, a estranheza provocada pela presença de uma mulher sozinha num bar está associada à divisão sexual do espaço. 0 espaço público só pode ser ocupado pela mulher heterossexual acompanhada de amigas e principalmente do marido ou namorado. Fora disso, a mulher é considerada disponível, indigna, imoral, numa postura machista compartilhada por homens e mulheres.

Muitos comentários foram feitos sobre o tema do programa:

Viviane Ferreira @Viviluminada 21 Jan 2014 Viewtranslation @ EncontroFatima acho que a atração pelas alianças, se torna fascinante pois aquele envolvimento não terá cobranças!

Ivanice de Paula @ivanicedepaula 21 Jan 2014 @EncontroFatima sou casada ha 23 anos e meu marido e eu, só usamos aliança no $1^{\circ}$ ano de casados. $\mathrm{O}$ elo q nos une é o amor e a confiança.

Flávia Souza @FlaviardeSouza 21Jan 2014 @EncontroFatima Antes, durante ou depois do relacionamento o importante é auto conhecimento, auto estima elevada, beneficia a saúde nas relações.

No Twitter, as opiniões das telespectadoras abordaram aspectos diferentes do assunto. O primeiro deles é o fato de alianças serem símbolo de união e amor. Para algumas, o uso é extremamente necessário. Para outras, o mais importante é o sentimento vivido do que o objeto usado. Há ainda aquelas que afirmam que a aliança possibilita o assédio:

Viviane Ferreira @Viviluminada 21 Jan 2014 @EncontroFatima acho que a atração pelas alianças, se torna fascinante pois aquele envolvimento não terá cobranças!

Jenny Souza @jennijeckson 21 Jan 2014 @EncontroFatima É verdade que as mulheres hoje estão mais atiradas, e isso assusta um pouco os homens? \#Encontro

Renata Medeiros @ReTrujillo 21 Jan 2014 @EncontroFatima mulher que gosta de homem comprometido é safada! Eu gosto de exclusividade, seja $\mathrm{p} 1$ noite ou pra vida td

Jaqueline Batista @Jackithahh 21 Jan 2014 @EncontroFatima O homem acha que a mulher com aliança é mais fácil de ficar, pois ela não vai querer compromisso e sim só uma aventura. 
É evidente a permanência do machismo nas representações do feminino pelas próprias mulheres. Enquanto as mulheres que se interessam pelos homens casados são safadas, os homens veem as mulheres casadas como mais fáceis de conquistar para uma aventura sexual. A formação discursiva do patriarcado ainda é tão poderosa que produz mulheres que menosprezam e desvalorizam as próprias mulheres em nome da forca da ordem masculina que se evidencia no fato de que ela dispensa justificação: "a visão androcêntrica impõe-se como neutra e não tem necessidade de se enunciar em discursos que visem legitimá-la" (Bourdieu, 1997, p. 9). Assim, as relações desiguais naturalizam a violência entre homens e mulheres, além da identificação do arbitrário cultural, da socialização diferenciadora, que insere os indivíduos - inclusive as próprias mulheres - na cultura masculinista. Noutras palavras, trata-se de um sistema social que produz sujeitos "com traços de gênero determinados em conformidade com um eixo diferencial de dominação, ou os produza presumivelmente masculinos" (Butler, 2016, p. 19).

\section{Considerações Finais}

Entender o gênero como os sentidos culturais constituídos pelo corpo sexuado exige considerar a descontinuidade entre este e aquele, apontando para a importância de reconhecer os meios através dos quais o programa Encontro com Fátima Bernardes atua como parte da formação discursiva que confere apenas à mulher a condição de "o sujeito da feminilidade" (Butler, 2016). Na produção, são atribuídas características, valores, competências específicas ao feminino, sempre como oposição ao masculino, com a prevalência da percepção do gênero como uma estrutura binária, ao lado do embaralhamento dos papéis sociais de mulher e de mãe, constituídos de forma indiferenciada, como se estivessem dados efossem intrínsecos ao gênero, em especial naqueles assuntos relativos à casa e família, pressupondo, exclusivamente, a parceria com homens.

Assim, as formas materiais do programa observadas através das diferentes mudanças de cenários ao longo do tempo, se revelam também articuladoras dessa binaridade agenciada e controlada pela apresentadora cuja trajetória profissional televisiva foi construída também a partir do seu significante como mãe e esposa. Tal escolha silencia e exclui, por exemplo, a existência de arranjos familiares formados por dois homens ou duas mulheres. Mesmo que não haja a negação total das composições homoafetivas, expostas em reportagens e entrevistas no estúdio, esta realidade social tem desativado parte do valor político do corpo sexuado cujo gênero não segue a heteronormatividade, ao exibi-lo como notícia, por irromper a materialidade social como "o outro", enquanto a relação binária homem-mulher é tornada central e hegemônica. 


\section{Referências}

AGAMBEN, Giorgio. 0 que é o contemporâneo? Chapecó: Argos, 2009.

ANDREZA. @EncontroFatima Sofri assédio moral e denunciei que bom que a justiça foi feita! 28 maio. 2013. Twitter: @Andreza37. Disponível em: https://twitter.com/ Andreza37. Acesso em: 10 mar. 2017.

BADINTER, Émile. Um amor conquistado: o mito do amor materno. Rio de Janeiro: Nova Fronteira, 1985.

BARTKY, Sandra. Foucault, Femininity, and the modernization of patriarchal power. In: DIAMOND, Irene; QUINBY, Lee (orgs.). Feminism and Foucault: reflections on resistance. Boston: Northeastern University Press, 1988.

BATISTA, Jaqueline. @EncontroFatima O homem acha que a mulher com aliança é mais fácil de ficar, pois ela não vai querer compromisso e sim só uma aventura. Brasil, 21 jan. 2014. Twitter: @Jackithahh. Disponível em: https://twitter.com/ Jackithahh. Acesso em: 12 mar. 2017.

BERNARDES, Fátima. In: REDE GLOBO. Encontro com Fátima [Adoção]. Rio de Janeiro: Rede Globo, 25 jun. 2012. Programa de TV. . In: . Encontro com Fátima [Mulheres separadas]. Rio de Janeiro: Rede Globo, 21 jan. 2014. Programa de TV. . In: . Encontro com Fátima [Volta de férias]. Rio de Janeiro: Rede Globo, 20 jan. 2014. Programa de TV.

BONI, Carmen. @EncontroFatima sim estou sofrendo mas resolvi estudar o comportamento humano já que vou me aposentar em 4 meses para superar e entender. Brasil, 28 maio. 2013. Twitter: @CarmenBoni. Disponível em: https:// twitter.com/CarmenBoni. Acesso em: 10 mar. 2017.

BOURDIEU, Pierre. A dominação masculina. Rio de Janeiro: Bertrand Brasil, 1997.

BRAZ, Caroline. @EncontroFatima Não sei se é considerado o assédio, mas minha chefe colocou a culpa do erro uma colega em mim, e ainda disse bem alto para.. Brasil, 28 maio. 2013. Twitter: @carolinebraz2. Disponível em: https:// twitter.com/carolinebraz2. Acesso em: 10 mar. 2017.

BUTTLER, Judith. Problemas de Gênero: feminismo e subversão da identidade. Rio de Janeiro: Civilização Brasileira, 2016.

CHARLOTTE, Sophie. In: REDE GLOBO. Encontro com Fátima [Mulheres separadas]. Rio de Janeiro: Rede Globo, 21 jan. 2014. Programa de TV. 
DA MATA, Vanessa. In: Encontro com Fátima [Adoção]. Rio de Janeiro: Rede Globo, 29 jun. 2012. Programa de TV.

DAUDT, Francisco. In: Encontro com Fátima [Mulheres separadas]. Rio de Janeiro: Rede Globo, 21 jan. 2014. Programa de TV.

DE PAULA, Ivanice. @EncontroFatima sou casada ha 23 anos e meu marido e eu, só usamos aliança no $1^{\circ}$ ano de casados. O elo q nos une é o amor e a confiança. Brasil, 21 jan. 2014. Twitter: @ivanicedepaula. Disponível em: https://twitter. com/ivanicedepaula. Acesso em: 12 mar. 2017.

DELDUQUE, Sabrin. @EncontroFatima não gostei não. Perdeu a marca do programa que era deixar o público perto. Assim, ficou igual aos outros!! Brasil, 27 maio 2013. Twitter: @sabrinabati. Disponível em: https://twitter.com/sabrinabati. Acesso em: 10 mar. 2017.

DOLORES, Juliana. @EncontroFatima esta lindo e de se emocionar... Brasil, 25 jun. 2012. Twitter: @julianadolores. Disponível em: https://twitter.com/julianadolores. Acesso em: 9 mar. 2017.

ESQUENAZI, Rose. No túnel do tempo: uma memória afetiva da televisão brasileira. Porto Alegre: Artes e Ofícios Ed, 1993.

FARIA, Ana Maria de. @EncontroFatima O programa está show!!!! Amei o destaque do tema adoção. Tenho um filho adotado, que chamo de filho do coração. Brasil, 25 jun. 2012. Twitter:‘@AnaMariadeFari2. Disponível em: https://twitter.com/ AnaMariadeFari2. Acesso em: 9 mar. 2017.

FERREIRA, Tainá. @EncontroFatima tenho um irmão adotado e não dou a mínima para isso, porque de alguma forma ele é meu irmão de sangue e amo como os outros. Brasil, 26 jun. 2012. Twitter: @Tainaferreira18. Disponível em: https:// twitter.com/Tainaferreira18. Acesso em: 9 mar. 2017.

FERREIRA, Thiago. In: REDE GLOBO. Encontro com Fátima [Assédio moral]. Rio de Janeiro: Rede Globo, 28 maio 2013. Programa de TV.

FERREIRA, Viviane. @EncontroFatima acho que a atração pelas alianças, se torna fascinante pois aquele envolvimento não terá cobranças! Brasil, 21 jan. 2014. Twitter: @Viviluminada. Disponível em: https://twitter.com/Viviluminada. Acesso em: 12 mar. 2017.

FREITAS, Milla. @EncontroFatima ESTOU ASSISTINDO, E JÁ CHORANDO DE TANTA EMOÇÃO COMO INICIO DO PROGRAMA.. PARABÉNS FATIMA. Brasil, 25 jun. 2012. Twitter: @MillaFreitas. Disponível em: https://twitter.com/millafreitas. Acesso em: 9 mar. 2017. 
FOUCAULT, Michel. Arqueologia do Saber. Rio de Janeiro: Forense Universitária, 2013. Microfísica do Poder. Rio de Janeiro: Edições Graal, 2011.

. O sujeito e o poder. In: DREYFRUS, Hubert; RABINOW, Paul (orgs.). Michel Foucault: uma trajetória filosófica para além do estruturalismo e da hermenêutica. Rio de Janeiro: Forense, 1995.

. Vigiar e punir: o nascimento da prisão. Petrópolis: Vozes, 1977.

FORNA, Aminatta. Mãe de todos os mitos: como a sociedade modela e reprime as mães. Rio de Janeiro: Ediouro, 1999.

FUREDI, Frank. Therapy culture: cultivating vulnerability in an uncertain age. London: Routledge, 2004.

GILL, Rosalind. Gender and the media. Cambridge: Polity, 2007.

HALL, Stuart. Quem precisa de identidade? In: SILVA, Tomaz Tadeu da. Identidade e diferença. Petrópolis: Vozes, 2000.

IMPRENSA: Jornalismo e Comunicação. São Paulo: Contexto, 2007.

ILLOUZ, Eva. Oprah Winfrey and the glamour of misery: an essay on popular culture. New York: Columbia University Press, 2003.

INACIO, Paula. @EncontroFatima Já fui vítima de assédio moral no meu trabalho, isso foi muito triste porque eu era muito jovem, era meu primeiro emprego! Brasil, 28 maio. 2013. Twitter: @PaulalnacioO. Disponível em: https://twitter. com/PaulalnacioO. Acesso em: 11 mar. 2017.

LUCIANA|. @EncontroFatima muito emocionada vendo o tema adoção, parabéns!!!!!! Brasil, 25 jun. 2012. Twitter: @LinoLuciana. Disponível em: https://twitter.com/ LinoLuciana. Acesso em: 10 mar. 2017.

LUNA, Naara. Natureza humana criada em laboratório: biologização e genetização do parentesco nas novas tecnologias reprodutivas. História, Ciências, Saúde Manguinhos, Rio de Janeiro, v. 12, n. 2, maio-ago, 2005.

MARINA. @EncontroFatima Tenho uma prima e ela e adotada e amamos muito ela, ela é uma das alegria que temos em nossa familia. Brasil, 25 jun. 2012. Twitter: @marininha_lindi. Disponível em: https://twitter.com/marininha lindi. Acesso em: 9 mar. 2017.

MEDEIROS, Renata. @EncontroFatima mulher que gosta de homem comprometido é safada! Eu gosto de exclusividade, seja p 1 noite ou pra vida td. Brasil, 21 jan. 2014. Twitter: @ReTrujillo. Disponível em: https://twitter.com/ReTrujillo. Acesso em: 12 mar. 2017. 
MESQUITA, Evandro. In: REDE GLOBO. Encontro com Fátima [Envelhecimento]. Rio de Janeiro: Rede Globo, 27 maio 2013. Programa de TV.

MOÇA. In:___. Encontro com Fátima [ Mulheres separadas]. Rio de Janeiro: Rede Globo, 21 jan. 2014. Programa de TV.

MOREIRA, Amanda. @EncontroFatima minha irma tem uma filha adotiva, que hoje tem 15 anos, a adotou com 4, mas o irmão não teve a mesma sorte, está no abrigo inda. Brasil, 27 jun. 2012. Twitter: @guinmoura. Disponível em: https://twitter. com/guinmoura. Acesso em: 8 mar. 2017.

NAVARRO,Tatiane. @EncontroFatima Emocionante o depoimento das crianças a espera de uma família. Brasil, 25 jun. 2012. Twitter:'@tatiane_navarro. Disponível em: https://twitter.com/tatiane navarro. Acesso em: 9 mar. 2017.

NAZA. @EncontroFatima minha irmã foi adotada com 9 meses. Hoje ela tem 25 anos. Deus fez ela nascer de outra mãe mas ela é igual a minha família. Brasil, 27 jun. 2012. Twitter: @Silveriu. Disponível em: https://twitter.com/Silveriu. Acesso em: 081 mar. 2017.

OUTEIRO, Regina Diniz. @EncontroFatima síndrome de pânico. Eu e mais 2 colegas passamos a tomar antidepressivos. Pena que naquela época não se falava em assédio... Brasil, 28 maio. 2013. Twitter: @REGINAOUTEIRO. Disponível em: https://twitter.com/REGINAOUTEIRO. Acesso em: 11 mar. 2017.

. @EncontroFatima Sofri assédio moral de uma gerente em um banco estatal. Todos os dias era o mesmo assunto: você vai ser transferida. Brasil, 28 maio. 2013. Twitter: @REGINAOUTEIRO. Disponível em: https://twitter.com/ REGINAOUTEIRO. Acesso em: 10 mar. 2017.

. @EncontroFatima Vai perder a função. Não perca tanto tempo no atendimento ao cliente. Resultado: cai numa depressão profunda. Brasil, 28 maio. 2013. Twitter: @REGINAOUTEIRO. Disponível em: https://twitter.com/ REGINAOUTEIRO. Acesso em: 10 mar. 2017.

PEREIRA, Bianca. @ EncontroFatima linda a casa nova amei a cadeira da Fátima. Brasil, 27 maio 2013. Twitter: @biancapereira56. Disponível em: https://twitter.com/ biancapereira56. Acesso em: 10 mar. 2017.

PERROT, Michele. Minha história das mulheres. São Paulo: Contexto, 2007.

PINHEIRO, Leo. Globo anuncia saída de Fátima Bernardes do Jornal Nacional. Veja Online. São Paulo, 1 dez. 2011. Disponível em: http://veja.abril.com.br/ entretenimento/globo-anuncia-saida-de-fatima-bernardes-do-jornal-nacional. Acesso em: 18 mar. 2017. 
PINHEIRO, Najara Ferrari; RECKZIEGEL, José Luís Carvalho. Magazines femininos televisivos: um formato híbrido do gênero magazine. In: XXIX Congresso Brasileiro de Ciências da Comunicação, 2006, Brasília. Anais... Brasília: UnB, 2006.

POLÓNIA, Luana. @EncontroFatima já sofri assédio moral por minha encarregada ter medo de ser substituída! Tive que ser mudada de sede e me dei muito bem! Brasil, 28 maio. 2013. Twitter: @lupolonia. Disponível em: https:// twitter.com/lupolonia. Acesso em: 11 mar. 2017.

POSSI, Luiza. In: REDE GLOBO. Encontro com Fátima [Mulheres separadas]. Rio de Janeiro: Rede Globo, 21 jan. 2014. Programa de TV.

PROCURADORA DO MINISTÉRIO PÚBLICO DO TRABALHO. In: Encontro com Fátima [Assédio moral]. Rio de Janeiro: Rede Globo, 28 maio 2013. Programa de TV.

RAMOS, Natália. In: Encontro com Fátima [Mulheres separadas]. Rio de Janeiro: Rede Globo, 21 jan. 2014. Programa de TV.

REDE GLOBO. Encontro com Fátima [Adoção]. Rio de Janeiro: Rede Globo, 28 jun. 2012. Programa de TV.

. Encontro com Fátima [Adoção]. Rio de Janeiro: Rede Globo, 29 jun. 2012. Programa de TV.

. Encontro com Fátima [Adoção]. Rio de Janeiro: Rede Globo, 2 jul. 2012. Programa de TV.

. Encontro com Fátima [Envelhecimento]. Rio de Janeiro: Rede Globo, 27 maio 2013. Programa de TV.

Encontro com Fátima [Assédio moral]. Rio de Janeiro: Rede Globo, 28 maio 2013. Programa de TV.

Encontro com Fátima. Rio de Janeiro: Rede Globo, 29 maio 2013. Programa de TV.

Encontro com Fátima [Volta de férias]. Rio de Janeiro: Rede Globo, 20 jan. 2014. Programa de TV.

Encontro com Fátima [ Mulheres separadas]. Rio de Janeiro: Rede Globo, 21 jan. 2014. Programa de TV.

. Encontro com Fátima. Rio de Janeiro: Rede Globo, 22 jan. 2014. Programa de TV.

. Encontro com Fátima. Rio de Janeiro: Rede Globo, 20 jul. 2016. Programa de TV. 
Encontro com Fátima. Rio de Janeiro: Rede Globo, 21 jul. 2016. Programa de TV.

Encontro com Fátima. Rio de Janeiro: Rede Globo, 22 jul. 2016. Programa de TV.

RENNÓ, Lair. In: REDE GLOBO. Encontro com Fátima [Envelhecimento]. Rio de Janeiro: Rede Globo, 27 maio 2013. Programa de TV.

. In:

. Encontro com Fátima [Mulheres separadas]. Rio de Janeiro: Rede Globo, 21 jan. 2014. Programa de TV.

RODRIGUES, Nara. @EncontroFatima Já passei por vários, mas eu me sentia tao acoada, que nao tinha estimulo nem pra recorrer! Brasil, 28 maio. 2013. Twitter: @nararod94528749. Disponível em: https://twitter.com/nararod94528749. Acesso em: 11 mar. 2017.

ROCHA, Júlio. In: REDE GLOBO. Encontro com Fátima [Mulheres separadas]. Rio de Janeiro: Rede Globo, 21 jan. 2014. Programa de TV.

SACRAMENTO, Igor. O espetáculo do trauma: narrativas testemunhais de celebridades sobre o bullying num programa de TV. Revista Contracampo, Niterói, v. 35, n. 2, ago.-nov. 2016. Disponível em: http://www.contracampo.uff.br/index.php/ revista/article/view/940/pdf. Acesso em: 11 mar. 2017.

SHATTUC, Jane. The talking cure: TV talk shows and woman. New York: Routledge, 1997.

SANDRA. @EncontroFatima Adorei a decoração nova. Brasil, 27 maio 2013. Twitter: @ carrijosandra. Disponível em: https://twitter.com/carrijosandra. Acesso em: 11 mar. 2017.

SAYONARA. @EncontroFatima Me emocionei muito com os depoimentos das crianças... Brasil, 25 jun. 2012. Twitter:'@sazinhaalc. Disponível em: https://twitter.com/ sazinhaalc. Acesso em: 10 mar. 2017.

SILVA, Eveline. @EncontroFatima tá lindo, mas perdeu o aconchego q a gente sentia da plateia ao seu redor. E o telão era lindo :/, mas é sempre bom mudar. Brasil, 27 maio 2013. Twitter: @eveline22silva. Disponível em: https://twitter. com/eveline22silva. Acesso em: 11 mar. 2017.

SILVA, Mirian Marada. @EncontroFatima Acho a adoção lindo, mas acho que o casal deve estar bem preparado! Pois a genética de cada indivíduo permanece. Sucesso! Bj. Piedade, 25 jun. 2012. Twitter:'@Miroks_2010. Disponível em: https://twitter. com/Miroks 2010. Acesso em: 8 mar. 2017. 
SILVEIRA, Ingrid. @EncontroFatima Por causa de assédio moral de uma ex-chefe, desenvolvi stress agudo e síndrome do pânico. Brasil, 28 maio. 2013. Twitter: @Ingrid_Silveira. Disponível em: https://twitter.com/Ingrid Silveira. Acesso em: 11 mar. 2017.

SOUZA, Flávia. @EncontroFatima Antes, durante ou depois do relacionamento o importante é auto conhecimento, auto estima elevada, beneficia a saúde nas relações. Brasil, 21 jan. 2014. Twitter: @FlaviardeSouza. Disponível em: https:// twitter.com/FlaviardeSouza. Acesso em: 12 mar. 2017.

SOUZA, Jenny. @EncontroFatima É verdade que as mulheres hoje estão mais atiradas, e isso assusta um pouco os homens? \#Encontro. Brasil, 21 jan. 2014. Twitter: @jennijeckson. Disponível em: https://twitter.com/jennijeckson. Acesso em: 12 mar. 2017.

SOUZA, Maria Aline. @EncontroFatima Estou ADORANDO o programa... e me emocionando muito com as estórias de adoção... PARABÉNS! Brasil, 25 jun. 2012. Twitter: @maria_line. Disponível em: https://twitter.com/maria line. Acesso em: 8 mar. 2017.

TELES, Lilia. In: REDE GLOBO. Encontro com Fátima [Adoção]. Rio de Janeiro: Rede Globo, 29 jun. 2012. Programa de TV.

VERAS, Marcos. In: REDE GLOBO. Encontro com Fátima [Envelhecimento]. Rio de Janeiro: Rede Globo, 27 maio 2013. Programa de TV.

VIEIRA, Joice Melo. Os filhos que escolhemos: discursos e práticas da adoção em camadas médias. 2010. 192 f. Dissertação (Mestrado em Antropologia) Instituto de Filosofia e Ciências Humanas, UNICAMP, Campinas, 2004.

VITOR, Avani. @EncontroFatima tive uma patroa q gostava muito de umilhar as pessoas, q eu tinha ate medo dela quando chegava. Brasil, 28 maio. 2013. Twitter: @ avanivitor. Disponível em: https://twitter.com/avanivitor. Acesso em: 11 mar. 2017.

WILLIAMS, Raymond. Cultura. Rio de Janeiro: Paz e Terra, 2000.

Marxismo e literatura. Rio de Janeiro: Paz e Terra, 1979.

Television: technology and cultural form. London: Routledge, 1997.

YOUNG, Iris. Throwing like a girl and other essays in feminist philosophy and female body experience. Bloomington: Indiana University Press, 1990. 
Recebido em: 5/4/2017

Aceito em: 20/4/2017

Endereço dos autores:

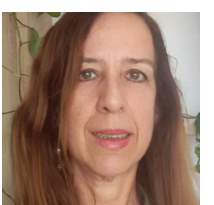

Jussara Peixoto Maia <jussaramaia@uol.com.br>

Universidade Federal do Recôncavo da Bahia

Rua Rui Barbosa, 710

44380-000 - Cruz das Almas (BA) - Brasil

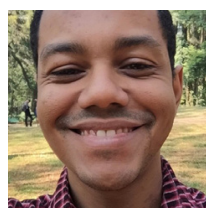

Igor Sacramento <igorsacramento@gmail.com>

Programa de Pós-Graduação em Comunicação e Cultura da Universidade Federal do Rio de Janeiro

(PPGCOM/UFRJ)

Av. Pasteur, 250 - Praia Vermelha

22290-240 - Rio de Janeiro (RJ) - Brasil

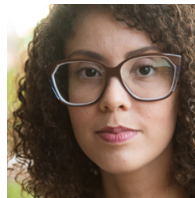

Valéria Vilas Bôas <lelavbs@gmail.com>

Programa de Pós-Graduação em Comunicação e Cultura Contemporâneas

Faculdade de Comunicação da Universidade Federal da Bahia (UFBA)

Av. Barão de Geremoabo, s/no - Campus de Ondina

40170-115 - Salvador (BA) - Brasil 